\title{
Commodity Currency: An Alternative Route to Currency Union
}

\author{
Ian McFarlane \\ School of Agriculture, Policy and Development, University of Reading, Reading, UK \\ Email: i.d.mcfarlane@reading.ac.uk
}

Received January 11, 2012; revised February 17, 2012; accepted February 27, 2012

\begin{abstract}
Proposals have been made for a common currency for East Asia, but the countries preparing to participate need to be in a state of economic convergence. We show that at least six countries of East Asia already satisfy this condition. There also needs to be a mechanism by which the new currency relates to other reserve currencies. We demonstrate that a numéraire could be defined solely from the actual worldwide consumption of food and energy per capita, linked to fiat currencies via world market prices. We show that real resource prices are stable in real terms, and likely to remain so. Furthermore, the link from energy prices to food commodity prices is permanent, arising from energy inputs in agriculture, food processing and distribution. Calibration of currency value using a yardstick such as our SI numéraire offers an unbiased measure of the consistently stable cost of subsistence in the face of volatile currency exchange rates. This has the advantage that the participating countries need only agree to currency governance based on a common standards institution, a much less onerous form of agreement than would be required in the creation of a common central bank.
\end{abstract}

Keywords: Commodity; Currency; Econometrics; Subsistence; Volatility

\section{Introduction}

For the trading nations of East Asia, the volatility of currency exchange rates is disruptive and costly. For several years, economists have given careful consideration to methods for stabilising intraregional exchange rates. Kawai [1] noted the emergence in East Asia of macroeconomic and structural convergence such as preceded the European monetary integration; this convergence has been acknowledged as a necessary condition, first identified by Mundell [2], for the introduction of a common currency. More specifically, Hsu [3] examined the feasibility of a common currency for Hong Kong, Korea, Malaysia, Philippines, Singapore and Thailand, and concluded that these six economies exhibited features that favoured adoption of region-wide monetary policies. Soo and Chung [4] re-investigated the behaviour of these six economies, concluding that segmentation had declined significantly.

After the USA unilaterally ended the direct convertibility of the dollar to gold in 1971, major currencies have floated, adding the burden of risk-management to all international contracting arrangements. Groen and Pesenti [5] reported the predictive power of exchange rates in formation of commodity prices. Clements and Fry [6] identified countries that are considered to have "commodity currencies", including Australia, New Zealand and Canada as well as some developing countries that are rich in natural resources. From empirical examination of real exchange rates and commodity prices 1975-2005 they found that spillovers from commodities to currencies contributed less than $1 \%$ to the volatility of currencies, while spillovers from currencies to commodities contributed between $2 \%$ and $5.2 \%$ to commodity price volatility.

The International Comparison Program (ICP) of the World Bank used purchasing power parity (PPP) instead of market exchange rates to convert currencies in order to compare the output of economies and the welfare of their inhabitants in real terms; Deaton and Heston [7] provided an overview of the ICP round for 2005, and drew attention to the quantity weighting of prices in the construction of composite world price indexes.

In this paper we briefly review the historic background of suggestions for an international numéraire for purchasing power. We apply econometric methodology to demonstrate the feasibility of an economic numéraire derived using physical SI units.

\subsection{Purchasing Power of Currencies}

Clements, Lan and Roberts [8] reviewed the risk-management challenges associated with international trade in resource-based products, and endorsed PPP as a long-run 
determinant of exchange rates. Taylor and Taylor [9] in an earlier discussion as to the relevance of the PPP concept to aggregate price indexes, made a distinction between producer prices and consumer prices, and demonstrated that the correlation between national price levels in Britain and Japan (similar countries each with their own currency) is much greater with producer prices than with consumer prices.

The relative version of long run PPP recognises that baskets of goods vary from country to country, and the arbitrage effect of commodity prices on exchange rates acts over periods of several years.

The International Monetary Fund (IMF) specified a currency valuation for the purpose of valuing the Special Drawing Rights (SDR) that it makes available as a reserve asset to supplement its member countries' official reserves [10]. The value of the SDR is defined as a basket of currencies, currently consisting of the euro, Japanese yen, pound sterling, and US dollar. It is calculated as the sum of specific amounts of the four basket currencies, and is thus a relative valuation. The basket composition is reviewed every five years.

\subsection{SI Units of Currency}

There have been a number of proposals for units for measurement of value with a physical basis, many of them stimulated by the work of Francois Quesnay (16941774), whose Tableau Economique of 1758 included units of corn and units of iron in a model of economic equilibrium between farmers producing agricultural commodities and artisans producing industrial commodities (Bilginsoy [11] ).

Defilla [12] proposed a value measurement unit, defined in SI units as the annual real cost of physiological energy consumption of a reference person at minimal activity, conveniently equivalent to Planck Energy, i.e. 1956.1 MJ (0.5433 MWh). Though attractive, the calculation of the cost of energy does not avoid the need for a "consumer basket" of energy; Defilla used a database of 24,249 disaggregated energy price observations from the Swiss Federal Statistics Office made in 2003, weighted according to use of electricity, gas and district heating.

Modern information systems offer the possibility of defining a unit of measurement of value with continual adjustment of weighting of reference data. Technology is also available, in the case of a weighted basket of commodities, to make the basket traceable to real goods defined within the Système-International d'unités (SI) maintained by the Bureau International des Poids et Measures (BIPM). The task of the BIPM is to ensure world-wide uniformity of measurements and their traceability; it does this with the authority of the Convention of the Metre, a diplomatic treaty between fifty-one nations.

\section{Currency Numéraires}

\subsection{History}

Cohen [13] identified the Peace of Westphalia, achieved in 1648 to end a war in Europe (The Thirty Years War), as setting the territorial pattern for state sovereignty, and thus, in Cohen's phrase, "the Westphalian model of monetary geography". He observed that in the modern era no government can ensure that its money alone will be used in preference to currencies originating elsewhere; currency domains are now set by the range of each money's effective use and authority.

There is a long history of proposals for use of a commodity basket as numéraire for purchasing power. Vivo [14] traced the path followed by Piero Sraffa in building the consistent wage-profit-price relations culminating in the publication of "Production of Commodities by Means of Commodities" [15], in which Sraffa explored the theory of a Standard Commodity produced by "itself and labour".

No agreement has yet been reached on a methodical system for valuing currencies in relation to one another, nor have the countries that have the privilege of seigniorage proposed any alternative to this convenient source of revenue.

\subsection{Resource Commodities}

Richard Cooper [16] suggested currency union among the major industrial democracies, now partially realised in the establishment of the European Central Bank and with it the European currency. Cooper more recently [17] foresaw that as international financial transactions continue to grow relative to growth in trade and services, financial factors will come to dominate exchange rate determination. Flexible rates, hitherto providing a useful mechanism for absorbing trade shocks and disturbances, have themselves become a source of financial shocks; Cooper suggested that this correspondingly makes wider currency union more beneficial than exchange rate flexibility.

Agricultural commodities are by their nature entirely replaceable, and agricultural economists can predict the marginal cost of producing approximately sufficient of each commodity to satisfy the market in the short term. Among such commodities there are numerous close substitutes in each category so that commodities that remain persistently in short supply are gradually replaced in dietary habits. Deaton and Laroque [18] used a statistical model of long-run behaviour of prices of primary commodities produced in poor countries, and concluded that commodity supply in the long run is infinitely elastic.

Commodities derived from mineral extraction are usually regarded as non-replaceable, to the extent that there is widespread concern that some sources will become 
exhausted. Economists recognise that the marginal cost of extraction rises as extraction becomes more difficult. The consequence of a persistent price rise is that consumers perceive an incentive to change consumption habits; the "oil price shocks" of recent times have stimulated investment in production of "renewable" energy sources.

Some minerals that are used in small quantities for specialised industrial purposes are less easy to replace as they run out; antimony, an essential input in manufacture of fire retardant material, is mainly found in the Republic of China, and as the extraction there becomes limited, antimony will be increasingly costly until exploration reveals alternative sources. Occurrence of antimony in the earth's crust is comparable to that of silver; silver production is more than 10 times greater than antimony production, reaching 709.6 Moz (20,118 t) in 2009, when 165.7 Moz (4698 t) of silver was recycled (Silver Institute, 2010). The ratio of recycled material to new extraction increases steadily for all precious metals; arbitrage operates to set the ratio such that the marginal costs of recycling and extraction are comparable (Ongondo et al. [19]).

\section{Example of a Calculated Numéraire}

As an example, we have calculated a numéraire defined solely in SI units, from the actual worldwide consumption of food and energy per capita, and linked to fiat currencies via representative world market prices.

Food security is a universal priority, and undernourishment refers to the condition of people whose dietary energy consumption is continuously below a minimum dietary energy requirement for maintaining a healthy life and carrying out a light physical activity with an acceptable minimum body-weight for attained-height. The UN FAO estimated 2620 food calories (10.97 MJ) per capita per day to be actual world food energy consumption in 2009 [20].

The quantity of energy $80 \mathrm{kWh} / \mathrm{cap} / \mathrm{d}$ used in the calculation of our results is about $64 \%$ of typical energy use in western Europe and Japan in 2004-2009. Mackay [21] observed that while unrestrained access to energy such as has been the situation in North America for decades leads to consumption of about $250 \mathrm{kWh} / \mathrm{cap} / \mathrm{d}$, the populations of Britain, western Europe and Japan have adapted to consumption patterns requiring about $125 \mathrm{kWh} / \mathrm{cap} / \mathrm{d}$. New information about the likely consequences of continuing emissions of greenhouse gases for the world climate has stimulated measures to restrain energy use, without denying to inhabitants of the rest of the world the possibility of achieving lifestyles requiring comparable consumption. Mackay concluded that efficiency measures can enable all countries to attain a European standard of living with consumption of $68 \mathrm{kWh} / \mathrm{cap} / \mathrm{d}$, and that it is realistic to suggest that $80 \mathrm{kWh} / \mathrm{cap} / \mathrm{d}$ for the entire world population is both feasible and sustainable.

\subsection{Expenditure on Food}

Weekly prices of traded food commodities from January 1999 to December 2009, compiled from data published by international exchanges and converted where necessary to US\$ at the exchange rate prevailing in each week, are used as proxy for the average international price level for each of 9 groups of diet constituents. Applying these prices to the quantities of each group consumed year by year, leads to a table of expenditures in US cents on food from each group summarised in Figure 1.

\subsection{Expenditure on Energy}

Weekly prices of traded units of fuel and energy from January 1999 to December 2009, compiled from data published by international exchanges, priced in various units and converted where necessary to US\$/GJ, are used as proxy for the average international price level for each of five groups of energy commodity prices. Applying these prices to the quantities of fuel actually consumed year by year leads to a table of weekly expenditures in US\$ summarised in Figure 2.

\subsection{Currency Valuation Using SI Numéraire}

The aggregate totals from both sets of results are depicted in Figure 3. Taken together, these are basic subsistence costs at wholesale commodity prices for a modest "western" lifestyle, sufficient for balanced nutrition, with expenditure sufficient for 2620 food calories/cap/d and $80 \mathrm{kWh} / \mathrm{cap} / \mathrm{d}$. The food energy component is at or below 50 US cents/cap/d throughout the 11 year period. By contrast, the energy cost rises from US\$1 to US\$3 during the 11 years.

The same total outlay but with cost converted at current exchange rates, obtained for each week from publicly reported rates, is presented in UK£/cap/d, €/cap/d

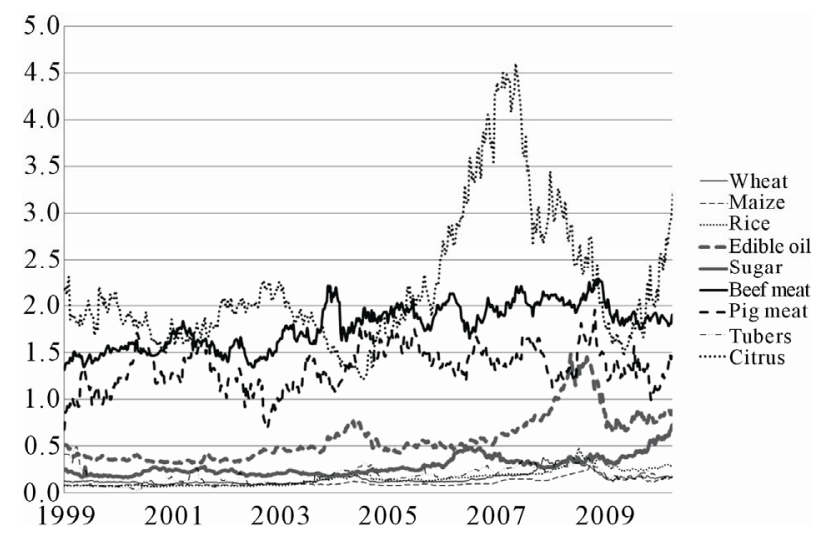

Figure 1. Expenditure on food required for subsistence, UScents/cap/d. 


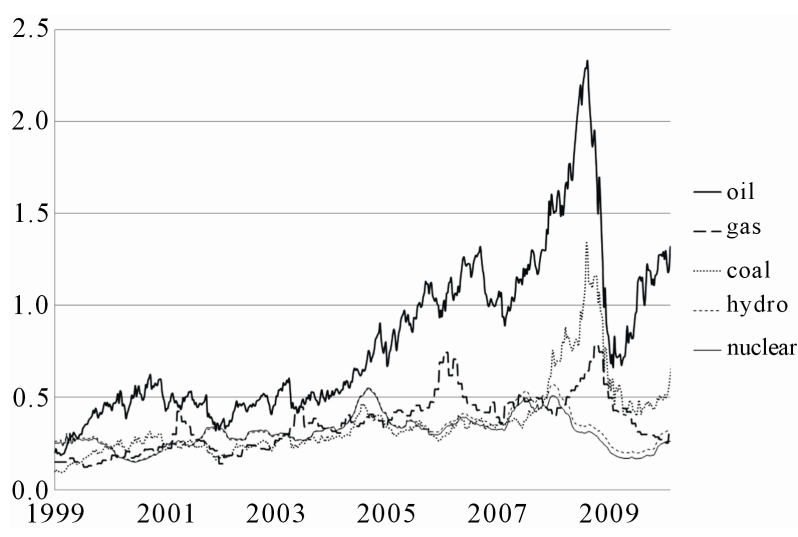

Figure 2. Expenditure on energy required for subsistence, US\$/cap/d.

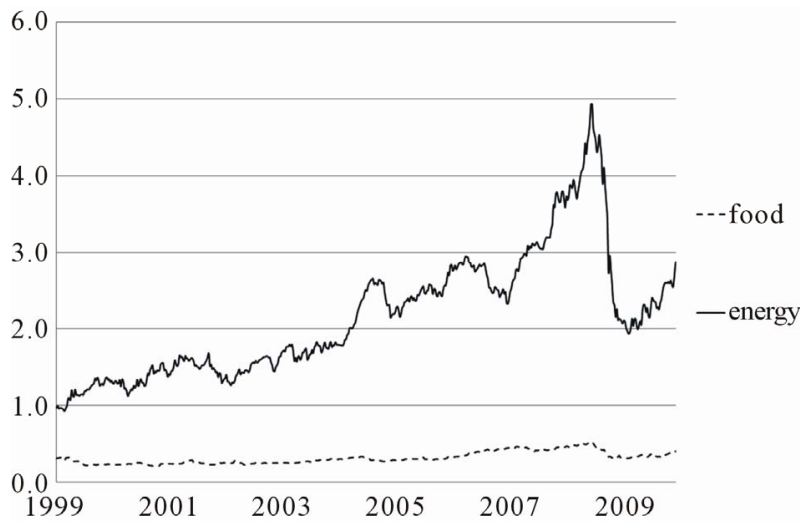

Figure 3. Aggregate subsistence costs, US\$/cap/d.

and $¥ / c a p / d$ together with US\$/cap/d in Figure 4.

The significance of our numéraire is shown in Figure 5, in which the data from Figure 4 is inverted, and the value of each currency is depicted as the number of days' subsistence that can be purchased with one unit of the currency. The common downward trend shows that increases in cost of energy, led by the price of oil, have diminished the purchasing power of all four currencies in the period 1999-2009.

\section{Discussion}

Prices used in this paper have not been adjusted for inflation, because deflator methods are based on baskets of goods or other form of compensation for changes in purchasing power. Our numéraire itself performs a corresponding role; the downward trend seen in Figure 5 is an indicator of change of value of units of currency in real terms.

\subsection{Food Preferences}

The short-term volatility in weekly prices of energy, shown in Figure 3, is accompanied by shocks that persist

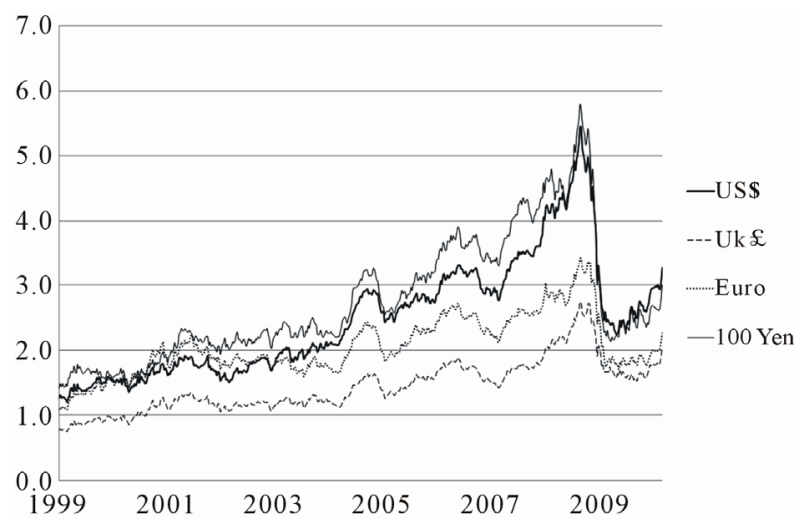

Figure 4. Aggregate subsistence costs in other currency.

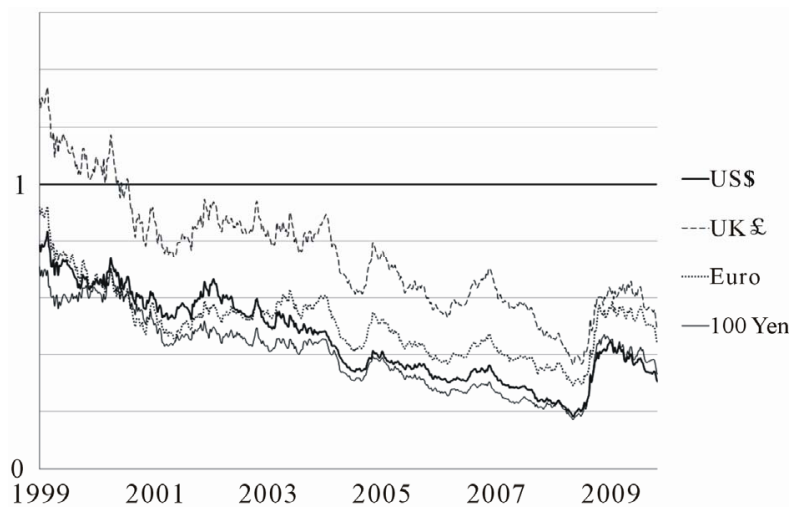

Figure 5. Days of subsistence affordable per unit of fiat currency.

for many months and have far-reaching consequences for the world economy. Energy being an input in food production, the major shocks are reflected in the cost of food.

Short-term volatility is also a feature of the series of weekly prices for individual food commodities. We used producer prices in preference to consumer prices on the evidence of Taylor and Taylor, referred to above, that producer prices are correlated internationally, as is appropriate for our purpose in proposing an international numéraire. Figure 3, in comparison with Figure 1, shows that the aggregate food prices are less volatile than individual prices; it is repeatedly found in surveys of household expenditure that food purchases are a stable component of household budgets, and so it is to be expected that aggregate consumer expenditure on food will be stable.

Our choice of representative foods as proxy for price of an entire group is arbitrary, and could be made less so by assembling more comprehensive data sets. Household food purchasing behaviour is studied frequently and in great detail; Lewbel [22] observed that a number of aggregation schemes are equally valid.

Sharif [23] identified subsistence as an endogenous 
variable, contrary to a tendency for economists to treat it as exogenous, and directly useful for practical policy purposes. Sharif contended that subsistence is endogenous to people who live at or around poverty level; they aspire to live at a sustainable standard, and their perception of this standard is revealed in their economic behaviour. The consistent physical food calorie intake of the world population thus provides a conveniently stable basis for assessing purchasing power, especially as flexibility in the composition of healthy diet permits substitution of close alternatives within food groups when individual items become scarce.

\subsection{Energy Markets}

Spot prices for energy in international markets are erratic. The coal price is the only one of the set to which normal market forces may be considered to apply. Prices for natural gas are typically set in long-term supply contracts. Our numéraire requires data for wholesale electricity from hydro and nuclear power sources, but the market makes no distinction between these sources, so we use the publicised price for wholesale electricity in the spot market for both sources.

The most significant market distortion is in the oil market, where the Organisation of the Petroleum Exporting Countries (OPEC) has recently celebrated fifty years of unchallenged oligopolistic market domination, with the stated mission: "to coordinate and unify the petroleum policies of its Member Countries and ensure the stabilization of oil markets in order to secure an efficient, economic and regular supply of petroleum to consumers, a steady income to producers and a fair return on capital for those investing in the petroleum industry".

There are many oil suppliers who are not associated with OPEC, and it is possible to find indications of their marginal costs of supply. If the market should ever be liberated, perhaps by introduction of substitutes for oil in some uses, economists would expect the international price for the equivalent of a barrel of crude oil to stabilise at the marginal cost of producing sufficient oil to meet worldwide demand. Almost unlimited oil can be extracted from tar sands in Canada, and the cost of production there could thus set an upper limit to oil prices in a free market. Extraction of crude oil has been reported in trade publications to cost in the range Can $\$ 30$ - Can $\$ 40$ per barrel, and potentially even less as technology is improved. The Canadian Energy Research Institute [24] has observed that oil sands extraction already on stream can be profitable at crude oil prices in the range of Can\$40 Can\$75 per barrel.

Fossil fuel consumers may soon be required to pay some form of "carbon tax". Reported suggestions for carbon tax are in the range US\$11 - US\$85/t CO $\mathrm{CO}_{2}$; this implies minimum tax of about \$13/barrel. Noting that the US Environmental Protection Agency Greenhouse Gases Equivalencies Calculator indicated an emission rate of $6.896 \times 10^{-4}$ metric tons $\mathrm{CO}_{2} / \mathrm{kWh}$ (equivalent to 191.5 $\mathrm{kg} \mathrm{CO} / \mathrm{GJ}$ or $1.17 \mathrm{t} \mathrm{CO}_{2} /$ barrel, using $3.6 \mathrm{MJ} / \mathrm{kWh}$ and $6.119 \mathrm{GJ} /$ barrel), this takes the marginal cost of supply to at least about $\$ 53 /$ barrel.

\section{Conclusions}

Exchange rates are more volatile than the real price of commodity goods, which strengthens the argument for adopting a unit of value based on one or more real physical commodities. The gold standard filled this need for a time, but gold has no definable relation to the value placed by a consumer on goods that are consumed. It is the cost of consumed commodities that determines whether an individual's income is sufficient for that individual's daily needs.

We stress again that our aggregation scheme for food and energy costs is not arbitrary, but is directly proportional in each case to measurable world consumption. We have shown that food commodity prices are stable in real terms, and likely to remain so. The duration of booms in food price is limited because supply is elastic and response times are relatively short. Market failure in the oil sector is at present preventing similar correction in energy prices, but the marginal cost of oil supply is predictable, likely to remain stable, and significantly lower than the wholesale oil price prevailing in 2010. Calibration of currency value using a yardstick such as our SI numéraire offers an unbiased measure of the consistently stable cost of subsistence in the face of volatile currency exchange rates.

We have thus shown that a commodity-based measure of monetary value is suitable as the basis of a currency unit for a group of countries, such as the countries of East Asia, with similarities in their patterns of consumption. There is as yet no data to indicate whether such a unit, specified by a standards agency rather than a banking institution, would indeed be inherently stable, but it would at least be free of the practice referred to as seigniorage, and the accompanying temptation to print money.

\section{Acknowledgements}

The author is grateful to the School of Agriculture, Policy and Development, University of Reading, for permission to make continuing use of the university research facilities.

\section{REFERENCES}

[1] M. Kawai, "The Role of an Asian Currency Unit for Asian Monetary Integration," Asian Development Bank 
Institute, 2008.

[2] R. A. Mundell, "A Theory of Optimum Currency Areas," American Economic Review, Vol. 51, No. 4, 1961, pp. 657-665

[3] H. Hsu, "Is a Common Currency Area Feasible for East Asia? A Multivariate Structural VAR Approach," 2011. http://www.osipp.osaka-u.ac.jp/archives/DP/2009/DP200 9E006.pdf

[4] S.-C. Soo and C.-K. Choong, "An Emergence of a Common Currency Area in the Selected East Asian Economies: A Revisit," Singapore Economic Review, Vol. 55, No. 2, 2010, pp. 353-376. doi:10.1142/S0217590810003778

[5] J. Groen and P. Pesenti, "Commodity Prices, Commodity Currencies and Global Economic Developments," Federal Reserve Bank of New York Staff Report No. 387, 2009.

[6] K. Clements and R. Fry, "Commodity Currencies and Currency Commodities," Resources Policy, Vol. 33, No. 2, 2008, pp. 55-73. doi:10.1016/j.resourpol.2007.10.004

[7] A. Deaton and A. Heston, "Understanding PPPs and PPPBased National Accounts," Working Paper 14499, NBER, Cambridge, 2008.

[8] K. Clements, Y. Lan and J. Roberts, "Exchange-Rate Economics for the Resources Sector," Resources Policy, Vol. 33, 2008, pp. 102-117. doi:10.1016/j.resourpol.2007.12.003

[9] A. Taylor and M. Taylor, "The Purchasing Power Parity Debate," Journal of Economic Perspectives, Vol. 18, No. 4, 2004, pp. 135-158. doi:10.1257/0895330042632744

[10] 1MF, "Special Drawing Rights," 2011. http://www.imf.org/external/np/exr/facts/pdf/sdr.pdf

[11] C. Bilginsoy, "Quesnay's Tableau Economique: Analytics and Policy Implications," Oxford Economic Papers, New Series, Vol. 46, No. 3, 1994, pp. 519-533.

[12] S. Defilla, "A Physical Unit for Value-Econophysics as Arbiter between Finance and Economics," 2006.

[13] B. J. Cohen, "The Geography of Money," Cornell UP, New York, 1998.
[14] G. de Vivo, "Sraffa's Path to Production of Commodities by Means of Commodities. An Interpretation," Contributions to Political Economy, Vol. 22, 2003, pp. 1-25. doi:10.1093/cpe/22.1.1

[15] P. Sraffa, "Production of Commodities by Means of Commodities: Prelude to a Critique of Economic Theory," Cornell UP, New York, 1960.

[16] R. N. Cooper, "A Monetary System for the Future," Foreign Affairs, Vol. 63, No. 1, 1984, pp. 166-184

[17] R. N. Cooper, "Exchange Rate Choices," Federal Reserve Bank of Boston, 1999 http://www.bostonfed.org/economic/conf/conf43/99p.pdf

[18] A. Deaton and G. Laroque, "A Model of Commodity Prices after Sir Arthur Lewis," Journal of Development Economics, Vol. 71, No. 2, 2002, pp. 289-310. doi:10.1016/S0304-3878(03)00030-0

[19] F. Ongondo, I. Williams and T. Cherrett, "How Are WEEE Doing? A Global Review of the Management of Electrical and Electronic Wastes," Waste Management Vol. 31, No. 4, 2010, pp. 714-730. doi:10.1016/j.wasman.2010.10.023

[20] FAO "World Calories-Total," 2011. http://www.fao.org/economic/ess/chartroom-and-factoids/ chartroom/93-world-calories-total/en/

[21] D. Mackay, "Sustainable Energy-Without the Hot Air," UIT, Cambridge, 2008.

[22] A. Lewbel, "Aggregation without Separability: A Generalised Composite Commodity Theorem," American Economic Review, Vol. 86, No. 3, 1996, pp. 524-543.

[23] M. Sharif, "A Behavioural Analysis of the Subsistence Standard of Living," Cambridge Journal of Economics, Vol. 27, No. 2, 2003, pp. 191-207. doi:10.1093/cje/27.2.191

[24] "Canadian Oil Sands Supply Costs and Development Projects (2010-2044)," Canadian Energy Research Institute Study No 122, 2011. http://www.ceri.ca/images/stories/CERI\%20Study\%2012 2.pdf 